University of Nebraska - Lincoln

DigitalCommons@University of Nebraska - Lincoln

\title{
Viewing Preschool Disruptive Behavior Disorders and Attention- Deficit/Hyperactivity Disorder through a Developmental Lens: What We Know and What We Need to Know
}

\author{
Anil Chacko \\ Queens College, City University of New York, anil.chacko@nyu.edu \\ Lauren Wakschlag \\ University of Illinois at Chicago, lauriew@northwestern.edu \\ Carri Hill \\ University of Illinois at Chicago, CHill@Erikson.edu \\ Barbara Danis \\ University of Illinois at Chicago, danisbarbara@gmail.com \\ Kimberly A. Espy \\ University of Nebraska-Lincoln, kespy2@unl.edu
}

Follow this and additional works at: https://digitalcommons.unl.edu/dcnlfacpub

Part of the Neurosciences Commons

Chacko, Anil; Wakschlag, Lauren; Hill, Carri; Danis, Barbara; and Espy, Kimberly A., "Viewing Preschool Disruptive Behavior Disorders and Attention-Deficit/Hyperactivity Disorder through a Developmental Lens: What We Know and What We Need to Know" (2009). Developmental Cognitive Neuroscience Laboratory Faculty and Staff Publications. 43.

https://digitalcommons.unl.edu/dcnlfacpub/43

This Article is brought to you for free and open access by the Developmental Cognitive Neuroscience Laboratory at DigitalCommons@University of Nebraska - Lincoln. It has been accepted for inclusion in Developmental Cognitive Neuroscience Laboratory - Faculty and Staff Publications by an authorized administrator of DigitalCommons@University of Nebraska - Lincoln. 
Published in Child and Adolescent Psychiatric Clinics of North America 18 (2009), pp. 627-643; doi:10.1016/j.chc.2009.02.003 Copyright (c) 2009 Elsevier Inc. Used by permission.

http://childpsych.theclinics.com

During preparation of this paper, Dr. Chacko was supported through a Klingenstein Third Generation ADHD Fellowship. Dr. Wakschlag, Dr. Hill, and Dr. Danis were supported by NIMH grants R01 MH68455 and MH62437 as well as by the Shaw and Children's Brain Research Foundations. Dr. Espy was supported in part by R01 MH065668, R01 DA014661, P01 HD 038051, and R01 HD050399.

\title{
Viewing Preschool Disruptive Behavior Disorders and Attention-Deficit/Hyperactivity Disorder through a Developmental Lens: What We Know and What We Need to Know
}

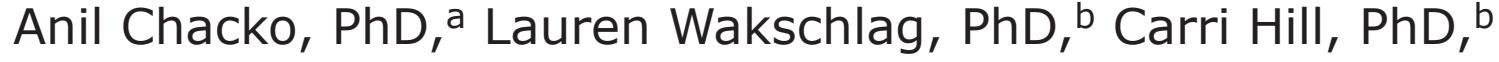 \\ Barbara Danis, PhD, ${ }^{\mathrm{b}}$ and Kimberly Andrews Espy, PhD c \\ a Department of Psychology, Queens College, City University of New York, 65-30 Kissena \\ Boulevard, Flushing, NY 11367, USA \\ b Department of Psychiatry, Institute for Juvenile Research, University of Illinois at Chicago \\ 1747 W. Roosevelt Road, MC 747 (Room 155), Chicago, IL 60608, USA \\ c Department of Psychology, University of Nebraska-Lincoln, 303 Canfield Administration \\ Building, Lincoln, NE 68588-0433, USA
}

Corresponding author - Anil Chacko, email anil.chacko@qc.cuny.edu

Summary/Abstract is found on page 638.

Keywords: disruptive behavior, ADHD, preschool, psychopathology, nosology

There is now little doubt that Diagnostic and Statistical Manual of Mental Disorders, fourth edition (DSM-IV), behavior disorders are present and are identifiable during the preschool years.1,2 With only minor modifications to DSM-IV disruptive behavior disorders (DBDs) and attention-deficit/hyperactivity disorder (ADHD) nosology, multiple, independent studies have shown similar prevalence rates and correlates as in 
older children. ${ }^{1}$ In the preschool-age range, these disorders also have modest stability. ${ }^{3-6}$ It is clear that the behaviors that comprise DBDs and ADHD (e.g., noncompliance, rule breaking, aggression, destruction of property, hyperactivity, inattention, and impulsivity) impair children's functioning and that caregivers of young children often experience considerable difficulty in managing children who exhibit high levels of these behaviors. Increasingly, preschoolers are being referred to mental health clinics for DBDS and ADHD, ${ }^{7}$ with escalating rates of pharmacologic treatments. ${ }^{8}$ Thus, $^{2}$ the "real-world" consequences of behavior disorders are substantial for young children and their families and often mark the onset of long-term developmental maladaptation that marks psychopathology. ${ }^{9}$ Concerted efforts to characterize the clinical manifestations of these disorders in early childhood more precisely will maximize our ability to intervene effectively in the lives of young children affected with DBDs and ADHD and, ultimately, to reduce their long-term health burden.

The increasing consensus that these syndromes exist in young children also comes with growing concern that these disorders may be developmentally misspecified, particularly for young children who are not at the extremes. ${ }^{10}$ In this article, we review the extant empirical evidence through a "developmental lens," with an eye to analyzing how the absence of a developmental approach may hinder accurate identification. Further, we show how integrating evidence from developmental science provides useful guideposts for generating and testing a developmentally specified nosology. Together with the plethora of work on preschool psychopathology during the past decade, this provides a strong foundation for charting a course for the next generation of more refined efforts in early childhood.

\section{Disruptive Behavior Disorders and Attention-Deficit/Hyperactivity Disorder: What We Know}

Although multiple, overlapping terms have been used for capturing behavioral syndromes, for the sake of clarity here, we will use the terms DBDs and ADHD when specifically referring to these clinical syndromes and the term "behavior disorders" to refer to the two syndromes collectively. The study of behavior disorders, has taken on two, somewhat distinct, lines. There is a long history of studies of "preschool behavior problems" that have generally used checklist ratings of externalizing behaviors, which combine disruptive attention/hyperactivity behaviors. ${ }^{9}$ Collectively, studies that have emphasized the dimensional classifications of disorders have informed the field tremendously by enhancing our understanding of the developmental nature of behavior problems in young children, the co-occurrence of various problems (e.g., impulsivity, noncompliance, aggression), the longitudinal course of these problems, and potential underlying mechanisms of these problems. ${ }^{9,11}$ More recently, DSM-IV nosology has been applied to preschoolers. ${ }^{2}$ Although the categorical approach of the DSM is not without limitations, we focus our review on DSM-defined DBDs and ADHD as a means of highlighting issues related to categorical identification, clinical significance, and service provision. Studies were included in this review if the following criteria were met: (1) DSM DBDs (oppositional defiant disorder (ODD) and/or conduct disorder [CD]) and/ or ADHD were assessed, (2) the majority of the sample was preschool age (3-5 years), and (3) data were reported on the prevalence, convergent validity or correlates, and/ or predictive validity of these disorders. We extend beyond existing reviews ${ }^{1,12}$ by incorporating more recent work with developmentally validated instruments, attempting to bridge preschool studies of DBDs and ADHD that come from somewhat different traditions and heretofore have proceeded along fairly separate lines, highlighting developmental limitations of existing work and linking to extant developmental science. 


\section{Disruptive Behavior Disorders}

\section{Prevalence}

In the absence of validated diagnostic instruments for use in this age period, a variety of instruments have been used for diagnosis in preschoolers. Early studies often used nonstandardized, relatively minor modifications of existing diagnostic instruments to determine diagnosis ${ }^{13,14}$ or determined diagnosis through clinical consensus using multiple and varied assessment information. ${ }^{15}$ Most recently, interviews specifically validated for the preschool period have been employed, including the Preschool Age Psychiatric Assessment (PAPA), ${ }^{3}$ in addition to other diagnostic tools (Kiddie Disruptive Behavior Disorders Schedule), which have been evaluated using clinical samples. ${ }^{16}$ Across community samples, prevalence rates of ODD have ranged from $4 \%$ to $16.6 \%$, which is similar to that found in older children. ${ }^{17}$ Importantly, although Lavigne and colleagues ${ }^{15}$ found the highest rates of ODD (i.e., 16.6\%), this rate was reduced in half when impairment associated with the symptoms was required for the diagnosis (i.e., 8.1\%). Thus, the presence of symptoms of DBDs alone is misleading, and interpreting the presence of symptoms as disorder likely results in higher prevalence of DBDs when impairment resulting from these symptoms is not taken into account. Assessment of impairment, however, is notably absent from most preschool DBD studies. To our knowledge, only two studies have assessed CD as a separate disorder in community samples of preschoolers, ${ }^{3,18}$ with rates somewhat lower than ODD (3.9\%-6.6\%), again, without considering impairment.

Age differences within the preschool period have received little attention. Although some studies ${ }^{3}$ have reported no age differences in prevalence rates, Lavigne and colleagues ${ }^{15}$ found a modest linear age trend in the prevalence of ODD during the preschool period. The prevalence of ODD as defined by the presence of four symptoms was $22.5 \%$ in 3 -year-old children but was only $15 \%$ in 5 -year-old children.

\section{Validity}

Determining the validity of a psychiatric diagnosis in multifaceted. Here, we focus on two important aspects: concurrent validity and predictive validity. Concurrent (also termed convergent) validity represents the extent to which a test or measure correlates highly with other variables with which it should theoretically correlate, whereas predictive validity is the extent to which a measured construct demonstrates a predictive relation to the same or a similarly measured construct over time (i.e., longitudinal stability of diagnostic status; 1 ). Predictive validity of a disorder, however, is a particularly challenging issue in young children, as substantial behavioral shifts occur from 3 to 5 years, and thus, normative frequencies may shift, making the determination of stability complex. Thus, if manifestation or frequencies of symptoms vary with age, the predictive validity (stability) of a disorder may be obscured. On the other hand, the rapid developmental shifts of this period may reduce stability.

Studies have demonstrated that key aspects of the family environment, parent psychopathology, parenting behavior, parent-child interactions, observed child behavior, child neuropsychological functioning, and social information processing differ among children with DBDs compared with typically developing children. ${ }^{18-31}$ These correlates are similar to those found in older youth with disruptive disorders. Not surprisingly, children who meet symptom criteria for DBDs also experience substantial impairment in these domains. ${ }^{3,16}$ 
Several investigators have also assessed predictive validity. Wakschlag and colleagues ${ }^{6}$ found that $55 \%$ of their clinically enriched sample retained DBD status at one-year follow-up. Speltz and colleagues ${ }^{20}$ assessed the 2-year stability of ODD and found that that the vast majority of children in their clinic-based sample $(76 \%)$ continued to meet criteria for ODD diagnosis 2 years later. In two papers, Lavigne and colleagues 29,31 report on the 2-year and 5-year follow-up results within their preschool, community-based sample. They reported that the 2-year stability of any behavior disorder (ODD, CD, and/or ADHD) or a combination of the three was moderate. Stability was higher for older preschoolers (65\% for 4 - to 5 -year-olds) than younger preschoolers (50\% for $2-3$-year-olds). It is not clear whether this is a true difference in stability, more "noise" in terms of transient variability in behavior at the younger preschool age, or due to the absence of developmentally specified cutoff points at these different ages. The diagnostic stability of ODD dropped substantially with longer follow-up-with stability of $43 \%, 27 \%$, and $24 \%$ at 3-, $4-$, and 5 -year follow-ups, respectively. Thus, the probability of a diagnosis of ODD during the school-age period was substantial if ODD was present during the preschool years. On the other hand, these data also demonstrate that most of the preschoolers (nearly half of the preschoolers with an ODD diagnosis at baseline) do not persist in meeting clinical criteria at school age. Similar patterns were reported by Kim-Cohen and colleagues ${ }^{18}$ on the 2 -year stability of CD in a community sample of children followed from 5 to 7 years of age. Meeting criteria for $C D$ at age 5 years significantly increased the odds of a CD diagnosis at age 7 years (odds ratio $=20.6$ ), with more boys retaining the CD diagnoses than girls. On the other hand, half of these children did not exhibit any CD symptoms at age 7 years, with $60 \%$ of these children failing to exhibit any CD symptoms at the subsequent age 10 years follow-up. ${ }^{32}$ Despite this relatively poor diagnostic stability, Kim-Cohen and colleagues ${ }^{18,32}$ report significant impairment in behavioral and academic functioning in these children. Collectively, although the short-term reliability of DBDs appears robust, the longer-term (2-5 year) stability of DBDs is questionable. As we discuss in greater detail in the second half of this paper, it is likely that the downward extension of DSM symptoms largely derived for school-age children to preschool children misspecifies the symptom presentation of DBDs in preschool children. Greater attention to this issue may assist in better defining DBDs in young children, which will result in more accurate identification and greater stability over time.

This lack of clear stability is a particularly critical issue for those interested in preventing poor long-term outcomes in children. As prevention and early intervention efforts are increasingly recognized as key to altering the often poor trajectories of youth with mental health disorders, ${ }^{33}$ identifying children who will have persistent disorder is essential. Providing often costly services to children whose difficulties are developmentally transient and who are not experiencing current distress or suffering does not maximize the use of valuable resources. Likewise, not identifying children who are likely to develop persistent problems and ultimately poor outcomes is equally, if not more, problematic. Reviews of the literature ${ }^{34}$ suggest that substantial misclassification results when the criterion of early onset symptoms of behavioral disorder assessed through parent and/or teacher self-report is applied to predict long-term development of disorder. Moreover, including pervasiveness or persistence does not result in improved identification of high-risk children. ${ }^{35}$ Although incorporating data from other key areas of risk that are associated with problematic longer-term outcomes (e.g., parental psychopathology) may prove useful in identifying children with the highest-risk, one potential avenue to pursue is improving on the developmental appropriateness of the symptoms used to capture behavioral disorders in young children. 
Lastly, diagnostic differentiation between ODD and CD in young children has rarely been investigated. Keenan and colleagues ${ }^{16}$ observed that virtually all preschoolers who met criteria for CD also met criteria for ODD. The one study that has examined the "fit" of this DSM diagnostic differentiation in preschoolers did not provide support for the ODD/CD distinction but rather for a unidimensional DBD construct. ${ }^{36}$ Taken together with the low stability of preschool-age CD symptoms ${ }^{18}$ and the attenuation of parent-reported CD symptoms over a 1 -week period, ${ }^{3}$ these data suggest that although multiple independent studies support the presence of DBDs at preschool age, considerably more work is needed to determine the validity of $C D$ as a distinct diagnostic entity in young children.

\section{ADHD}

\section{Prevalence}

Estimating prevalence rates of DSM-defined ADHD in preschoolers is often challenging, as an ADHD diagnosis requires symptoms to be present in more than one setting, but many young children are not in school. Thus, assessing for ADHD depends on the extent to which preschoolers spend a considerable portion of their day outside of parental care. Prevalence rates from community and pediatric clinic samples of preschoolers for ADHD range from $2 \%$ to $18.2 \%, 3,12-15,37-39$ with a range from $2 \%$ to $9.5 \%$ in pediatric samples, which are in line with prevalence rates for older youth. ${ }^{17}$ Clearly, differences in prevalence rates of preschool ADHD between studies are a function of the type of assessment conducted, with clinical consensus and structured interviews resulting in lower prevalence rates. The use of DSM-referenced symptom checklists resulted in higher prevalence rates, which is not surprising given that these checklists typically do not assess additional DSM criteria necessary for a diagnosis (e.g., presence of impairment; pervasiveness across settings). These additional criteria for an ADHD diagnosis may pose a significant issue in early childhood. For instance, the issue of pervasiveness across settings as a criterion is a good example of the extent to which "downward" extensions of existing criteria may obscure meaningful patterns in young children, because they do not reflect the "context" of early childhood. Although this issue has received scant attention in the preschool period, more recent instruments do incorporate developmentally appropriate consideration of the context. For example, the PAPA has adapted criteria for pervasiveness across settings by requiring that ADHD symptoms to occur in at least 2 activities and be, at least sometimes, uncontrollable by the child or by adult admonition.

Prevalence data are relatively sparse regarding specific ADHD subtypes in young children. ${ }^{3,12,37-39}$ First, the hyperactive/impulsive type is most commonly observed in preschool children, followed by ADHD combined type. Studies suggest that ADHD inattentive type is relatively rare in the preschool-age range; however, again this raises issues of the developmental sensitivity of symptoms as most of the inattentive symptoms in the current nosology focus on school-based tasks. When significant inattentive symptoms are endorsed, these symptoms usually co-occur with hyperactive-impulsive symptoms. To our knowledge, only one study has assessed age effects on ADHD diagnosis, with results demonstrating that the combined type ADHD was more commonly diagnosed in older preschool children. ${ }^{12}$

\section{Validity}

Numerous studies have assessed the convergent validity of DSM-defined ADHD in preschoolers. ${ }^{13,40-47}$ Similar to what is observed in older youth with ADHD, preschool- 
ers with ADHD have poorer social skills, more difficulties with their peers, greater academic difficulties, and poorer cognitive and neuropsychological functioning. Moreover, their parents often have greater levels of psychopathology and stress, negative parenting behavior, feel less competent in their role as parent, and have poorer coping styles.

To date, Lahey and colleagues 5,47 have conducted the most extensive studies of stability of DSM ADHD and ADHD subtypes. Lahey and colleagues ${ }^{47}$ found that $75 \%$ to $85 \%$ of 4 - to 6 -year-old preschool children meeting ADHD criteria initially retained this diagnosis during the following three subsequent years. Over the course of an 8-year follow-up, the proportion of youth who retained an ADHD diagnosis decreased in a pattern similar to that observed in older children. ${ }^{48}$ Additionally, children who initially met criteria for either the inattentive or hyperactive/impulsive subtype alone were more likely not to meet ADHD diagnosis at follow-up assessment compared with children who initially met criteria for ADHD combined type. For those children who continued to meet ADHD diagnosis, there was considerable instability in DSM ADHD subtypes. Collectively, these findings call into question the reliability and utility of the DSM nominal categories of ADHD in young children. As Lahey and colleagues ${ }^{5}$ note, "the subtypes cannot be viewed as discrete (nominal) categories that are permanent over time." Perhaps, as the authors state, continuous measures of ADHD symptoms, particularly the hyperactive/impulsive symptoms that appear to vary considerably over time, would be an appropriate diagnostic qualifier to classifying ADHD subtypes. It is clear that although the broad ADHD diagnosis has utility as a diagnostic entity in young children, further study must be conducted on the longer-term outcomes of preschool children with ADHD to best determine the utility of DSM ADHD subtypes. Alternatively, as we discuss later, an approach that includes a more developmentally specified definition of ADHD symptoms may better capture the presentation of ADHD in young children. Ultimately, greater precision in our conceptualization of ADHD symptoms for younger children is needed to clarify issues of subtypes and stability.

\section{DBDS and ADHD: Applying a Developmental Analysis}

Does the extant literature suggest that the road ends here for our understanding of DBDs and ADHD in early childhood? We have suggested that it does not.10,49,50 The early approach of "adhering as closely as possible to DSM-IV" with only minor developmental modifications ${ }^{2}$ was a critical first step in broadly establishing syndromal coherence that extends down to early childhood. This process has demonstrated that young children can experience clinically relevant and pervasive behavior problems, which warrant attention and further investigation. With this accomplished, however, narrowly constraining the conceptualization of behavior disorder phenomenology to the existing nosology may contribute to misspecification in early childhood. We have suggested that accurate identification during this developmental period requires a developmentally specified approach to establish the critical features of behavior disorders that distinguish symptoms from the normative misbehavior of early childhood. ${ }^{6,10}$ This developmentally specified approach would include elements such as identifying unique criterial features of behavior disorders in young children, establishing duration and symptom criteria cutoff points to generate maximally sensitive and specific thresholds, and defining symptom parameters in a manner that sharpens the typical: atypical distinction. In the following section, we apply a developmental lens to elucidate this approach. 


\section{Developmentally Imprecise, Impossible, Improbable, and Inappropriate}

Many DBD and ADHD symptoms overlap substantially with the normative misbehaviors of early childhood (e.g., often interrupts, loses temper, defies adults; 51). For instance, Egger, Kondo, and Angold ${ }^{12}$ found that many preschoolers met school-age cutoff criteria for the symptoms of "often loses temper" (30\%), "often interrupts or intrudes" (47\%), and "often actively defies" (57\%), respectively. Moreover, Pavuluri and colleagues ${ }^{51}$ found that parents rated $48 \%$ and $65 \%$ of preschoolers as "often easily distracted" and "often talking excessively," respectively. Although this is particularly true for ODD and ADHD, even some CD symptoms that are generally defined as more serious, low-incidence behaviors may be prevalent in young children. For example, Keenan and colleagues ${ }^{16}$ found that a significant number of nonreferred preschool children without behavioral concerns met DSM-IV symptom criteria for "uses object to harm" (14\%) and "often lies" (20\%). Further, these symptoms are defined solely by frequency ("i.e., often") during a period in which the presence of these behaviors per se is not pathognomonic. ${ }^{49}$ In addition to developmental specification of frequency cutoff points, the quality of behavior (e.g., its intensity, responsivity to environmental modification) may be important for such typical/atypical distinctions during the preschool period. ${ }^{10,49}$ Symptoms that overlap with commonly occurring misbehaviors of young children without specification of how frequently they must occur in order for these behaviors to be of clinical concern and/or criterial clinically defining features beyond frequency are developmentally imprecise. Developmental imprecision is likely to contribute to overidentification, because normative misbehaviors (such as temper tantrums and defiance) may be mistakenly considered symptoms.

In contrast, many DSM symptoms (CD in particular) are developmentally impossible for young children (e.g., truancy; 10). Others are developmentally improbable: although preschoolers may be capable of these behaviors (i.e., stealing with confrontation), they represent extreme forms of behavior that are unlikely to occur and are not likely to be the critical defining features at this young age. ${ }^{10}$ Thus, reformulating these symptoms to capture the underlying construct being assessed in a manner that better reflects the preschool-age period is necessary. In addition, some symptoms, particularly those for ADHD, are developmentally inappropriate (e.g., often fails to give close attention to details or makes careless mistakes in schoolwork, work, or other activities; does not follow through on instructions and fails to finish schoolwork, chores, or duties in the workplace; often loses things necessary for tasks or activities). Developmental inappropriateness occurs when constructs that are more easily assessed in school-age children versus preschool children are included in the psychiatric nosology. For instance, for DSM ADHD symptoms of inattention, the inattentive symptoms focus on distraction, which is too diffuse and may be more challenging to measure precisely in young children. Thus, this "developmental inappropriateness" may lead to underidentification of inattentive subtypes during early childhood.

Although no studies to date have examined patterns of sensitivity and specificity of the existing DSM-IV nosology for preschoolers (e.g., false positives, false negatives, subsequent onsetters, remitters), it is likely that developmentally impossible, improbable, and inappropriate symptoms contribute to underidentification of certain children as well as entirely missing children who may have a disorder. This is because (a) dropping "impossible" symptoms leads to a restricted item pool; (b) "improbable" symptoms are likely to capture only a small number of preschoolers with extreme manifestations and (c) "inappropriate" symptoms are not likely to effectively capture these behaviors in the manner they are present in most young children. For instance, con- 
clusions that the ADHD-inattentive type does not occur (or is not a meaningful subtype) in preschoolers may be premature in the absence of developmentally appropriate operationalization of symptoms.

Given the rapid growth young children experience during early childhood in language, cognitive skills, executive functioning, moral reasoning, and self-regulation, ${ }^{52}$ elucidating the parameters, presentation, meaning, and occurrence of the behaviors that define disruptive and attentional syndromes during this developmental period is particularly complex. Fortunately, major strides in developmental science over the past few decades have provided substantial evidence of the sequenced unfolding of these capacities in early childhood. ${ }^{53-57}$ Although a comprehensive review is beyond the scope of this article, 10,50 the following sections briefly describe the developmental underpinnings of core processes that underlie the defining behaviors of DBDs and ADHD. These "clues" from developmental science provide a critical foundation toward the goal of a developmentally specified nosology for preschool behavior disorders.

\section{Aggression}

As posited by Tremblay and colleagues, ${ }^{58}$ aggression during early childhood peaks during the toddler period but is "unlearned," resulting in a normative decline of aggression over time, as self-control, language, and adaptive problem-solving skills are acquired with maturation. Thus, persistently high levels of aggression across early childhood are not normative. This suggests that mere frequency of aggression during early childhood is likely not informative-moving beyond subjective frequency (i.e., "often") to determine normative frequency patterns within this developmental period is critical for demarcating the clinical threshold as well as for determining whether this differs at various ages across early childhood.

\section{Temper Loss}

The quality of tantrums has also been identified as clinically discriminating both in distinguishing disruptive from normative behavior and in distinguishing DBDs from other disorders. ${ }^{59}$ These qualities, including intensity of anger expressions, destructive tantrums, and difficulty recovering, have been linked to clinical problems in young children. ${ }^{10,59-61}$ Frequency, although important, is not in and of itself a key indicator of disorder in young children. Likely a combination of both developmentally inappropriate frequency of tantrums (determined across the preschool-age range) in addition to the quality of the tantrum can best help determine whether a tantrum of particular preschool child is concerning.

\section{Noncompliance}

As in the case of tantrums, developmental studies have focused on quality of noncompliance as a key distinction between typical and atypical manifestations. ${ }^{62-64}$ Normative noncompliance is characterized by affectively regulated, goal-directed, adaptive behaviors, which are responsive to adult redirection. In contrast, problematic noncompliance has been defined as active resistance to control and refusal that is often associated with negative affect. $61,64,65$ This includes "doing the opposite" of what was asked, an automatic, reflexive "no," and noncompliance in the context of angry outbursts. ${ }^{50}$

The clinical implications of these developmental patterns for both tantrums and noncompliance are that taking quality of misbehavior into account is likely to be critical to developing empirically based parameters for distinguishing disruptive behavior symp- 
toms in a developmentally sensitive manner in early childhood. Identifying the interactional context of normative misbehaviors may also be clinically discriminating. ${ }^{49}$

\section{Attention}

Disruptive behaviors are discrete and relatively easily defined (e.g., loses control of temper, hits another child). Although there are issues in how the construct of disruptive behavior varies with development, there is little question as how to define the problem behaviors in question. In contrast, the two main constructs of ADHD, inattention and impulsivity/hyperactivity, both involve "control" and are mixed to include cognitive and behavioral aspects. For example, attention is typically considered a cognitive ability, and yet in ADHD it is defined behaviorally by distractibility, poor persistence across time, and so on. Impulsivity includes both acting without thinking and reward-driven disinhibition, whereas hyperactivity typically is considered to reflect increased motor activity level, although it is rarely measured objectively in clinical settings. Not surprisingly, these measurement issues have precluded adequate specification of the key control processes across early development.

Attention is a basic cognitive construct, which is surprisingly difficult to define. Although aspects of focused, obligatory attention are evident in infancy, ${ }^{66}$ there are marked developmental changes in the control of attention during the preschool years. ${ }^{67,68}$ Ruff, Capozzoli, and Weissberg ${ }^{69}$ conducted a series of seminal studies on the development of sustained visual attention in preschool children. Importantly, the set of studies attempted to determine developmental trends in attention in several different situations (i.e., free play, television viewing, and reaction time task), to assess attention, consistency within, and stability across situations. Attention is typically considered a biologically based cognitive skill that is "endogenous" and thus should be highly consistent across contexts. In fact, however, attention is no different from compliance and temper behaviors in its dependence on context. Attention across different contexts is not as stable within individuals as attention measured in the same context across time. Clinically, these results highlight that individual differences in attention during the preschool period observed by assessment in one setting may be problematic for capturing clinically relevant attention problems.

Furthermore, it is not clear how actively sustaining attention differs from executive control. Indeed, a single latent factor has recently been found to underlie performance in inhibitory and working memory tasks 70 in typically developing preschool children, although preschoolers diagnosed with ADHD show deficits across task conditions when it is manipulated experimentally to load on motor inhibition (Go-No-Go Task) or sustained attention (Continuous Performance Task ${ }^{71}$ ). Most studies to date in preschoolers with ADHD have shown deficits in control processes, some more in attention, some more in motor, and some in control in light of reward. ${ }^{72}$ Collectively, it is clear that in the preschool-age range, children with ADHD have difficulty controlling behavior or cognition in light of expectation or instructions, although whether this difficulty is related to "attention," "executive function," or "motivation" is not clear.

\section{Impulsivity and Activity Level}

Impulsivity is most often defined at the behavioral level as the inability to delay, inhibit, or control behavior in light of reward or direction. At the behavioral level, developmentally, these behaviors have been lumped under the rubric of self-regulation or effortful control. Kochanska and colleague's ${ }^{73-76}$ studies of effortful control (i.e., low levels of impulsivity, although Kochanska's conceptualization of effortful control also includes effortful attention and control of motor activity) demonstrated significant de- 
velopmental progress in effortful control across the preschool period such that by 45 months, effortful control was highly stable and appeared to be a trait-like characteristic of young children. Thus, effortful control (i.e., impulsivity), unlike attention in young children, appears to be less affected by setting or context.

Activity level has been less studied but also shows similar developmental patterns. In one of the few studies on the development of hyperactivity, Romano and colleagues ${ }^{77}$ in a large national survey of parents of young children found that there were 4 trajectories depicting hyperactivity in children from the age of 2 to $6 / 7$ years. Data indicated that a small proportion of the children $(4.5 \% ; n=132)$ exhibited very few initial hyperactive symptoms, which decreased to zero over time. A significant number of children $(42.0 \% ; n=1,237)$ also exhibited few initial hyperactive symptoms, which remained at a low level over time. An equally substantial number of children $(46.3 \% ; n=1,365)$ exhibited moderate initial levels of hyperactivity, which declined slightly over time. Finally, a small number of children $(7.2 \% ; n$ $=212$ ) exhibited high initial levels of hyperactivity at age 2 years, and this level increased slightly over time. The data clearly demonstrate that hyperactivity, even in young children, is not uniformly high. In fact, $90 \%$ of young children have low to moderate levels of hyperactivity, which decrease over time. Clearly more data are necessary on understanding the presentation of hyperactivity in young children beyond the assessment of frequency.

\section{Charting a Developmentally Refined Nosology for DBDS and ADHD}

As we have discussed at several points throughout this paper, there is an opportunity to better capture the phenomena of DBDs and ADHD as manifested in the early childhood period, particularly by applying a more "bottom-up," developmentally driven approach to the specification of symptoms, with an emphasis on quality of the behavior (intensity, expectability in context, flexibility, and organization of behavior). For instance, although "is often angry and resentful" is a symptom of ODD, a more developmentally sensitive specification of the underlying construct of anger in young children may include "Gets angry or mad for no reason," "loses control when angry," and/or "has trouble calming down when angry." 10 These multiple definitions of temper loss are derived from incorporating the developmental literature on the quality of anger in young children as pathognomic rather than just frequency of anger outbursts. Thus, these developmentally driven definitions of temper loss may more precisely capture the specific facets of temper loss that are clinically discriminating in young children. Likewise, current ADHD symptoms of inattention (e.g., often has difficulty sustaining attention in tasks or play activities), hyperactivity (e.g., often talks excessively) and impulsivity (often interrupts or intrudes on others) could alternatively be captured by symptoms of dyscontrol, such as "difficulty with controlling attention to the relevant rule in one-to-one play activities," "cannot control talking in situations when remaining quiet is expected (e.g., story book reading) over short periods of time," and "cannot desist in interrupting others when provided structure and support to participate in engaging activities," respectively. These alternative symptoms define clinical patterns in reference to developmentally expectable tasks and capabilities in early childhood. Although these examples represent potential developmentally sensitive specifications of DBD and ADHD symptoms for young children, to date these are theoretically derived and will require systematic linkage to distributional characteristics of these behaviors within this developmental period and empirical validation of the incremental utility of a developmentally specified approach. 
Do Developmentally Specified Refined Symptoms of DBDs and ADHD Add Value and How Would We Know?

Revision of existing $\mathrm{DBD}$ and ADHD criteria specifically for young children requires strong justification. As Moffitt and colleagues 78 contend, altering an established nosology may alter "patient's access to health care and educational services, confuse the use of diagnosis on the courts and undermine the cumulative nature of scientific research into mental disorders." Thus, there must be substantial evidence that a change in symptom specification leads to incremental benefits compared with the standard specification documented in the DSM. We propose that developmental specification will provide substantial incremental value, but, of course, this requires empirical validation. ${ }^{10}$ First, developmental specification of symptoms is likely to substantially enhance accurate identification, thus increasing sensitivity, specificity, and stability of symptoms. As Bennett and colleagues 34,35 contend, our ability to provide intervention to those in greatest need depends greatly on accurate identification of children who are on the beginnings of a chronic disruptive behavior trajectory. Currently, relatively poor prediction from preschool disruptive behavior does not provide adequate targeted, prevention efforts.

\section{Treatment}

Over the past 2 decades, there has been an increasing evidence base for both psychosocial and pharmacologic interventions for DBDs and ADHD in preschoolers. ${ }^{79-81} \mathrm{Al}-$ though a comprehensive review of this literature is beyond the scope of this article (see articles in this issue), we highlight here some key findings of the primary psychosocial intervention for which there is substantial evidence of validity in preschoolers, specifically, Behavioral Parent Training (BPT). ${ }^{79,82,83}$

BPT has been evaluated as a treatment for ODD, CD, and ADHD in children as young as 2 years old, demonstrating significant reductions in observed and parent-reported behavioral problems ${ }^{84-89}$ and inattentive and hyperactive behavior. ${ }^{84,90}$ Moreover, beyond statistical significance, studies demonstrate that some preschool children attain clinically significant (i.e., normalization of behavior) benefits from BPT. ${ }^{91,92}$ BPT has also been shown to reduce punitive parenting behavior $86,89,92$ and parenting stress, 84,93 and to increase positive parenting behavior ${ }^{91}$ and parenting sense of competence. ${ }^{86,91}$ Furthermore, maintenance of treatment gains for some preschool children has been seen for periods ranging from a few months 84,86 to a year ${ }^{94}$ or more. ${ }^{87,89,95}$ Some studies have demonstrated continued improvement for these children after termination of treatment. ${ }^{87}$ Moreover, studies have shown that BPT for preschool children with ODD/CD has a broader impact for targeted children and their families. For example, studies have demonstrated effects of BPT on the school behavior of targeted preschool children ${ }^{85}$ as well as improving the behavior of nontargeted siblings. ${ }^{91,96}$ Collectively, the evidence suggests that BPT should be a first-line treatment for preschool-aged children who are at risk for or are diagnosed with ODD, CD, or ADHD.

The clear evidence for BPT for DBDs and ADHD must also be kept in light of the fact that a substantial minority of children do not respond to BPT. ${ }^{97,98}$ Although multiple reasons have been posited, we note that the lack of developmental specification of DBD and ADHD symptoms potentially undermines the efficacy of BPT and other interventions (e.g., stimulant medication). For example, we noted earlier that noncompliance per se is not pathognomic but can be adaptive and developmentally appropriate for preschoolers. However, developmentally, certain expressions of noncompliance, in 
particular the reflexive "no" and noncompliance in the context of angry outbursts, are problematic. Thus, if we only target BPT to those children who, developmentally, have maladaptive noncompliance, we are likely maximizing the effectiveness of BPT. Likewise, implementing BPT for children with developmentally appropriate expressions of noncompliance is a misuse of costly services. Similarly, when multiple expressions of developmentally maladaptive behavior exist, such as noncompliance as reflexive "no" versus noncompliance in the context of anger, developing targeted interventions based on the varying expression of the behavior can lead to better-tailored treatment. For instance, a reflexive "no" may be considered more temperamentally/ biologically driven and thus perhaps more responsive to pharmacologic intervention, whereas noncompliance in the context of anger may suggest the utility of implementing psychosocial interventions that focus on assisting parents to support emotional regulation in their child. Although space prohibits further elaboration of the treatment implications of developmental specifications of DBD and ADHD symptoms, we believe that this approach has great potential to obtaining a greater understanding of how best to treat young children with DBDs and ADHD.

\section{Summary}

Although DSM-defined DBDs and ADHD manifest during early childhood in meaningful ways, the emphasis of extending the DBD and ADHD nosology, which is based on studies of older youth, to younger children potentially limits the utility of these symptoms. Given that it is clear that DBDs and ADHD often emerge during early childhood and that early intervention is most efficacious, developing a more refined understanding of the clinical phenomenology of behavior disorders in early childhood is a critical next step. We contend that an approach that emphasizes the developmental specification of symptoms has the potential to address several long-standing issues in the literature, including enhancing the specificity, sensitivity, and stability of DBD and ADHD symptoms. Moreover, progress toward developmentally specified symptoms may inform our understanding of which type of treatment works best for whom. Answers to these questions are critical if we are to ultimately intervene to improve the lives of young children affected with DBDs and ADHD.

\section{References}

1. Keenan K, Wakschlag L. Can a valid diagnosis of disruptive behavior disorder be made in preschool children? Am J Psychiatry 2002;159:351-8.

2. Task Force on Research Diagnostic Criteria: Infancy and Preschool. Research diagnostic criteria for infants and preschool children: The process and empirical support. J Am Acad Child Adolesc Psychiatry 2003;42(12):1504-12.

3. Egger $H$, Erkanli $E$, Keelr $G$, et al. Test-retest reliability of the Preschool Age Psychiatric Assessment (PAPA). J Am Acad Child Adolesc Psychiatry 2006; 45(5):538-49.

4. Lahey B, Pelham W, Stein M, et al. Validity of DSM-IV attention-deficit/hyperactivity disorder for young children. J Am Acad Child Adolesc Psychiatry 1998; 37:695-702.

5. Lahey B, Pelham W, Loney J, et al. Instability of DSM-IV subtypes of ADHD from preschool through elementary school. Arch Gen Psychiatry 2005;62:896-902.

6. Wakschlag L, Briggs-Gowan M, Hill C, et al. Observational assessment of preschool disruptive behavior, part II: validity of the Disruptive Behavior Diagnostic Observation Schedule (DB-DOS). J Am Acad Child Adolesc Psychiatry 2008;47(6):632-41. 
7. Wilens T, Biederman J, Brown S, et al. Psychiatric comorbidity and functioning in clinically referred preschool children and school-age youths with ADHD. J Am Acad Child Adolesc Psychiatry 2002;41:262-8.

8. Zito J, Safer D, dosReis $S$, et al. Trends in the prescribing of psychotropic medications to preschoolers. JAMA 2000;283:1025-30.

9. Campbell SB. Behavior problems in preschool children: clinical and developmental issues. New York: Guilford; 2002.

10. Wakschlag L, Tolan P, Leventhal B. Research review: 'ain't misbehavin': towards a developmentally-sensitive nosology for preschool disruptive behavior. Invited review, forthcoming. J Child Psychol Psychiatry 2008, in press.

11. Shaw D, Gilliom M, Ingoldsby $E$, et al. Trajectories leading to school age conduct problems. Dev Psychol 2003;39(2):189-200.

12. Egger $\mathrm{H}$, Kondo $\mathrm{D}$, Angold $\mathrm{A}$. The epidemiology and diagnostic issues in preschool attention-deficit/hyperactivity disorder. Infants Young Child 2006; 19(2):109-22.

13. Keenan K, Shaw DS, Walsh B, et al. DSMIII-R disorders in preschool children from lowincome families. J Am Acad Child Adolesc Psychiatry 1997;36:620-7.

14. Briggs-Gowan M, Horowitz S, Schwab-Stone M. Mental health in pediatric settings: distribution of disorders and factors related to service use. J Am Acad Child Adolesc Psychiatry $2000 ; 39(7): 841-9$.

15. Lavigne J, Gibbons R, Christoffel K, et al. Prevalence rates and correlates of psychiatric disorders among preschool children. J Am Acad Child Adolesc Psychiatry $1996 ; 35(2): 204-14$.

16. Keenan K, Wakschlag L, Danis B, et al. Further evidence of the reliability and validity of DSM-IV ODD and CD in preschool children. J Am Acad Child Adolesc Psychiatry 2007;46:457-68.

17. American Psychiatric Association. Diagnostic and statistical manual for mental health disorders. Washington, DC: APA Press; 2000.

18. Kim-Cohen J, Arseneault L, Caspi A, et al. Validity of DSM-IV conduct disorder in 4 1/2-5 year-old children: a longitudinal epidemiological study. Am J Psychiatry 2005; 162:1108-17.

19. Speltz M, DeKlyen M, Greenberg M. Clinic referral for oppositional defiant disorder: relativeness significance of attachment and behavioral variables. J Abnorm Child Psychol 1995;23:487-507.

20. Speltz M, McLellan J, DeKlyen M, et al. Preschool boys with oppositional defiant disorder: clinical presentation and diagnostic change. J Am Acad Child Adolesc Psychiatry $1999 ; 38: 838-45$.

21. Coy K, Speltz M, DeKlyen M. Social cognitive processes in boys with and without oppositional defiant disorder. J Abnorm Child Psychol 2001;29(2): 107-19.

22. Greenberg M, Speltz M, DeKlyen M. Correlates of clinic referral for early conduct problems: variable- and person-oriented approaches. Dev Psychopathol 2001; 13:255-76.

23. Schwebel D, Speltz M, Jones K. Unintentional injury in preschool boys with and without early onset of disruptive behavior. J Pediatr Psychol 2002;27(8):727-37.

24. Wakschlag L, Keenan K. Clinical significance and correlates of disruptive behavior symptoms in environmentally at risk preschoolers. J Clin Child Adolesc Psychol $2001 ; 30: 262-75$.

25. Webster-Stratton C. Early-onset conduct problems: does gender make a difference? J Consult Clin Psychol 1996;64(3):540-51.

26. Webster-Stratton C, Lindsay D. Social competence and conduct problems in young children: issues in assessment. J Clin Child Adolesc Psychol 1999; 28(1):25-43.

27. Keenan K, Wakschlag L. More than the terrible twos: the nature and severity of behavior problems in clinic-referred preschoolers. J Abnorm Child Psychol 2000;28:33-46. 
28. Keenan K, Wakschlag L. Are ODD and CD symptoms normative behaviors in preschoolers? A comparison of referred and non-referred children. Am J Psychiatry 2004;161:356-8.

29. Lavigne J, Arend R, Rosenbaum D, et al. Psychiatric disorders with onset in the preschool years: I. Stability of diagnoses. J Am Acad Child Adolesc Psychiatry 1998;37:1246-54.

30. Lavigne J, Arend R, Rosenbaum D, et al. Psychiatric disorders with onset in the preschool years: II. Correlates and predictors of stable case status. J Am Acad Child Adolesc Psychiatry $1998 ; 37(12): 1255-61$.

31. Lavigne J, Cicchetti C, Gibbons R, et al. Oppositional defiant disorder with onset in preschool years: longitudinal stability and pathways to other disorders. J Am Acad Child Adolesc Psychiatry 2001;40:1393-400.

32. Kim-Cohen J, Arseneault L, Newcombe R, et al. Five-year predictive validity of DSMIV conduct disorder research diagnosis on $41 / 2$-5-year-old children. Eur Child Adolesc Psychiatry, in press.

33. Surgeon General, 2000 U.S. Public Health Service. Report of the Surgeon General's Conference on Children's Mental Health: a National Action Agenda. Washington, DC: Department of Health and Human Services; 2000.

34. Bennett K, Lipman E, Racine Y, et al. Annotation: do measures of externalizing behavior in normal populations predict later outcome? Implications for targeted interventions to prevent conduct disorder. J Child Psychol Psychiatry 1998; 39(8):1059-70.

35. Bennett K, Lipman E, Brown S, et al. Predicting conduct problems: can high-risk children be identified in kindergarten and grade 1? J Consult Clin Psychol 1999; 67(4):470-80.

36. Sterba S, Egger $H$, Angold A. Diagnostic specificity and nonspecificity in the dimensions of preschool pathology. J Child Psychol Psychiatry 2007;48(10): 1005-13.

37. Pineda $D$, Ardila $A$, Rosselli $M$, et al. Prevalence of attention-deficit/hyperactivity disorder symptoms in 4-17 year old children in the general population. J Abnorm Child Psychol 1999;27(6):455-62.

38. Gimpel G, Kuhn B. Maternal report of attention-deficit/hyperactivity disorder symptoms in preschool children. Child Care Health Dev 2000;26:163-79.

39. Gadow K, Sprafkin J, Nolan E. DSM-IV symptoms in community and clinical preschool children. J Am Acad Child Adolesc Psychiatry 2001;40:1383-92.

40. Dewolfe N, Byrne J, Bawden H. ADHD in preschool children: parent-rated psychosocial correlates. Dev Med Child Neurol 2000;42:825-30.

41. Byrne J, DeWolfe N, Bawden H. Assessment of attention deficit hyperactivity disorder in preschoolers. Child Neuropsychol 1998;4:49-66.

42. DuPual G, MCgoey K, Eckert T. Preschool children with attention-deficit/hyperactivity disorder: impairments in behavioral, social, and school functioning. J Am Acad Child Adolesc Psychiatry 2001;40(5):508-15.

43. Hartung C, Willcutt E, Lahey B. Sex differences in young children who meet criteria for attention-deficit/hyperactivity disorder. J Clin Child Adolesc Psychol 2002;31(4):453-64.

44. Chronis A, Lahey B, Pelham W, et al. Psychopathology and substance use in parents of young children with attention-deficit/hyperactivity disorder. J Am Acad Child Adolesc Psychiatry 2003;42:1424-32.

45. Lee S, Lahey B, Owens E, et al. Few preschool boys and girls with ADHD are well-adjusted during adolescence. J Abnorm Child Psychol 2008;36:373-83.

46. Massetti G, Lahey B, Pelham W, et al. Academic achievement over 8 years among children who met modified criteria for attention-deficit/hyperactivity disorder at 4-6 years of age. J Abnorm Child Psychol 2008;36:399-410.

47. Lahey B, Pelham W, Loney J, et al. Three-year predictive validity of DSM-IV attentiondeficit/hyperactivity disorder in children diagnosed at 4-6 years of age. Am J Psychiatry 2004;161:2014-20. 
48. Barkley R, Fischer M, Smallish L, et al. The persistence of attention-deficit/hyperactivity disorder as a function of reporting source and definition of disorder. J Abnorm Psychol 2002;111:279-89.

49. Wakschlag L, Leventhal B, Thomas B. Disruptive behavior disorders \& ADHD in preschool children: characterizing heterotypic continuities for a developmentally informed nosology for DSM V. In: Narrow W, First M, Sirovatka P, et al, editors. Age and gender considerations in psychiatric diagnosis: a research agenda for DSM-V. Arlington (VA): American Psychiatric Association; 2007. p. 243-58.

50. Wakschlag L, Danis B. Characterizing early childhood disruptive behavior: enhancing developmental sensitivity. In: Zeanah $\mathrm{C}$, editor. Handbook of infant mental health, 3rd edition. New York: Guilford. In press.

51. Pavuluri M, Luk S, McGee R. Parent reported preschool attention deficit hyperactivity: measurement and validity. Eur Child Adolesc Psychiatry 1999;8(2):126-33.

52. National Research Council and Institute of Medicine. From neurons to neighborhoods: the science of early childhood development. Washington, DC: National Academy Press; 2000.

53. Baillargeon R, Normand C, Seguin J, et al. The evolution of problem and social competence behaviors during toddlerhood: a prospective population based study. Infant Ment Health J 2007;28:12-38.

54. Brownell D, Kopp M, editors. Socioemotional development in the toddler years: transitions and transformations. New York Guilford.

55. Espy K, Bull R, Martin J, et al. Measuring the development of executive control with the shape school. Psychol Assess 2006;18(4):373-81.

56. Kochanska G, Aksan N. Children's conscience and self-regulation. J Pers 2006; 74:1587-617.

57. Tremblay R. The development of aggressive behaviour during childhood: what have we learned in the past century? Int J Behav Dev 2000;24(2):129-41.

58. $\mathrm{Co}^{\wedge} \mathrm{t}$ _e $\mathrm{S}$, Vaillancourt $\mathrm{T}$, LeBlanc J, et al. The development of physical aggression during childhood: a nation wide Joint development of physical and indirect aggression 53 longitudinal study of Canadian children. J Abnorm Child Psychol 2006;34:71-85.

59. Belden A, Thompson N, Luby J. Temper tantrums in healthy versus depressed and disruptive preschoolers: defining tantrum behaviors associated with clinical problems. J Pediatr 2008;152:117-22.

60. Needleman R, Stevenson J, Zuckerman B. Psychosocial correlates of severe temper tantrums. J Dev Behav Pediatr 1991;12:77-83.

61. Crockenberg S, Litman C. Autonomy as competence in 2 year olds: maternal correlates of child defiance, compliance, and self assertion. Dev Psychol 1990; 26:961-71.

62. Dirks M, Henry D, Hill C, et al. Contextual variations in preschoolers' social skills during laboratory observations: Implications for real world functioning.

63. Drabick D, Strassberg Z, Kees M. Measuring qualitative aspects of preschool boys' noncompliance: the response style questionnaire (RSQ). J Abnorm Child Psychol 2001;29:129-40.

64. Kuczynski L, Kochanska G. Development of children's noncompliance strategies from toddlerhood to age five. Dev Psychol 1990;26:398-408.

65. Bates J, Petit G, Dodge $\mathrm{K}$, et al. Interaction of temperamental resistance to control and restrictive parenting in the development of externalizing behavior. Dev Psychol $1998 ; 34: 982-95$.

66. Sheese $B$, Rothbart $M$, Posner $M$, et al. Executive attention and self-regulation in infancy. Infant Behav Dev 2008;31:501-10.

67. Reuda M, Posner M, Rothbart M. The development of executive attention: Contributions to the emergence of self-regulation. Dev Neuropsychol 2005;28(2): 573-94. 
68. Ruff $H$, Rothbart M. Attention in early development: themes and variations. New York: Oxford University Press; 1996.

69. Ruff H, Capozzoli M, Weissberg R. Age, individuality, and context as factors in sustained visual attention during the preschool years. Dev Psychol 1998;34(3): 454-64.

70. Wiebe S, Andrews K, Charak D. Using confirmatory factor analysis to understand executive control in preschool children: I. Latent structure. Dev Psychol 2008; 44(2):575-87.

71. Berwid O, Kera E, Marks D, et al. Sustained attention and response inhibition in young children at risk for attention-deficit/hyperactivity disorder. J Child Psychol Psychiatry 2005;46(11):1219-29.

72. Sonuga-Barke E, Auerbach J, Campbell S, et al. Varieties of preschool hyperactivity: multiple pathways from risk to disorder. Dev Sci 2005;8(2):141-50.

73. Kochanska G, Coy K, Murray K. The development of self-regulation in the first four years of life. Child Dev 2001;72(4):1091-111.

74. Kochanska G, Murray K, Harlan E. Effortful control in early childhood: continuity and change, antecedents, and implications for social development. Dev Psychol $2000 ; 36: 220-32$.

75. Kochanska G, Knaack A. Effortful control as a personality characteristic of young children: antecedents, correlates, and consequences. J Pers 2003;71(6): 1087-112.

76. Murray K, Kochanska G. Effortful control: factor structure and relation to externalizing and internalizing behavior. J Abnorm Child Psychol 2002;30:503-14.

77. Romano E, Tremblay R, Abdeljelil F, et al. Development and prediction of hyperactive symptoms from 2-7 years in a population-based sample. Pediatrics 2006; 117:2101-11.

78. Moffitt T, Arseneault L, Jaffee S, et al. Research review: DSM-IV conduct disorder: research needs for an evidence base. J Child Psychol Psychiatry 2008;49(1): 3-33.

79. Nixon R. Treatment of behavior problems in preschoolers: a review of parent training programs. Clin Psychol Rev 2002;22:525-46.

80. McGoey KE, Eckert T, DuPual G. Early intervention for preschool-age children with ADHD: a literature review. J Emot Behav Disord 2002;10(1):14-30.

81. Greenhill LL, Posner K, Vaughan BS, et al. Attention deficit hyperactivity disorder in preschool children. Child Adolesc Psychiatr Clin N Am 2008;17:347-59.

82. Eyberg S, Nelson M, Boggs S. Evidence-based psychosocial treatments for children and adolescents with disruptive behavior. J Clin Child Adolesc Psychol 2008;37(1):215-37.

83. Pelham WE, Fabiano GA. Evidence-based psychosocial treatments for attentiondeficit/ hyperactivity disorder. J Clin Child Adolesc Psychol 2008;37(1):184-214.

84. Eisenstadt TH, Eyberg S, McNeil CB, et al. Parent-child interaction therapy with behavior problem children: relative effectiveness of two stages and overall treatment outcome. J Clin Child Adolesc Psychol 1993;22(1):42-51.

85. McNeil CB, Eyberg S, Eisenstadt $\mathrm{TH}$, et al. Parent-child interaction therapy with behavior problem children: generalization of treatment effects to the school setting. J Clin Child Adolesc Psychol 1991;20(2):140-51.

86. Schuhmann EM, Foote RC, Eyberg SM, et al. Efficacy of parent-child interaction therapy: interim report of a randomized trial with short-term maintenance. J Clin Child Adolesc Psychol 1998;27(1):34-45.

87. Webster-Stratton $\mathrm{C}$. The effects of father involvement in parent training for conduct problem children. J Child Psychol Psychiatry 1985;26(5):801-10.

88. Webster-Stratton C. Enhancing the effectiveness of self-administered videotape parent training for families with conduct-problem children. J Abnorm Child Psychol $1990 ; 18(5): 479-92$.

89. Webster-Stratton C, Hammond M. Predictors of treatment outcome in parent training for families with conduct problem children. Behav Ther 1990;21:319-37. 
90. Sonuga-Barke EJS, Daley D, Thompson M, et al. Parent-based therapies for preschool attention-deficit/hyperactivity disorder: a randomized controlled trial with a community sample. J Am Acad Child Adolesc Psychiatry 2001;40:402-12.

91. Eyberg SM, Boggs SR, Algina J. New developments in psychosocial, pharmacological, and combined treatments of conduct disorders in aggressive children. Psychopharmacol Bull 1995;31:83-91.

92. Webster-Stratton C, Hammond M. Treating children with early-onset conduct problems: a comparison of child and parent training interventions. J Consult Clin Psychol 1997;35:93-108.

93. Pisterman $S$, Firestone $P, M c G r a t h ~ P$, et al. The role of parent training in treatment of preschoolers with ADHD. Am J Orthop 1992;62:397-408.

94. Funderburk BW, Eyberg S, Newcomb K, et al. Parent-child interaction therapy with behavior problem children: maintenance of treatment effects in the school setting. Child Fam Behav Ther 1998;20(2):17-39.

95. Webster-Stratton C. Long-term follow-up of families with young conduct problem children: from preschool to grade school. J Clin Child Adolesc Psychol 1990;19: 144-9.

96. Brestan EV, Eyberg SM, Boggs SR, et al. Parent-child interaction therapy: parents' perceptions of untreated siblings. Child Fam Behav Ther 1997;19:13-29.

97. Chacko A, Wymbs BT, Flammer-Rivera L, et al. A pilot study of the feasibility and efficacy of the strategies to enhance positive parenting program for single mothers of children with ADHD. J Atten Disord 2008;12(3):270-80.

98. Chacko A, Wymbs BT, Arnold FW, et al. Enhancing traditional behavioral parent training for single-mothers of children with ADHD. J Clin Child Adolesc Psychol in press. 